\section{Effect of knowledge of set size on search termination in long-term memory*}

\author{
EUGENE WINOGRAD \\ Emory University, Atlanta, Ga. 30322
}

Ss were asked to list all the states whose names began with the letter " $M$ " or "N." One group was told how many state names actually belonged to each set, while the other group was not told. The informed group worked at the task twice as long as the uninformed group and retrieved significantly more state names. The results were related to the problem of specifying quitting rules in recall.

The distinction between item accessibility and item availability (Tulving \& Pearlstone, 1966) implicates retrieval deficiencies in accounting for the inequality between what is actually recalled (accessible) and what is theoretically in storage (available). One aspect of the retrieval process that has received little experimental attention in this regard is the termination of recall by $S$. Obviously, it would be grossly inefficient, if not pathological, to continue to actively search for information presumed to be in storage in the face of continued failure. One commonly gives up the attempt to recall a name, for instance, in favor of some more rewarding task, even though one is confident that the item sought is in memory.

Atkinson \& Shiffrin (1968) are among the few theorists who have considered search termination at all. They suggest possible quitting rules $S s$ in recall experiments may adopt.

The work reported here demonstrates that knowledge of the number of items in an exhaustive set, all the members of which may be reasonably assumed to be in storage, can be a determinant of search termination and, hence, of recall scores. \section{METHOD}

Two exhaustive sets containing eight items each were used. They are the names of the states of the U.S. beginning with the letters $M$ and $N$. Group I, the instructed group, was told before recalling either the $\mathrm{M}$ or $\mathrm{N}$ states that there were eight such states. Group NI, the noninstructed group, was not told the set size in either case. All Ss in each group first attempted the states beginning with one letter and then those beginning with the other letter. The order was counterbalanced so that half of the Ss in each group attempted the $M$ states first.

\footnotetext{
* This research was supported by Grant GB-8771 from the National Science Foundation. The author is indebted to Alan Goldman for his assistance.
}

Both groups were told to write down as many of the appropriate states as they could, and "When you have finished, give me the paper." If $S$ had not quit after $4 \mathrm{~min}$, he was told to stop. There was a 3-min arithmetic task interpolated between recall of the two sets of states for each group.

Twenty undergraduates from the Emory introductory psychology course served as Ss in each of the two groups as part of a course requirement. They were randomly assigned to groups and tested individually. RESULTS

Table 1 shows the mean number of words retrieved and the median time spent working for the two groups. Although retrieval of $\mathrm{N}$ states was better than that of $M$ states ( $N$ states tend to be subcategorized into those states starting with "New" and "North"), the superiority for $N$ states is nearly identical for the groups. Hence, the data for the two letter categories for each $S$ were combined for purposes of statistical analysis. Because of the skewness of the distributions, a nonparametric test was used in comparing Groups I and NI. The Mann-Whitney test gave $U=40.5$ for items recalled and $U=40.0$ for total time, $p<.01$ in both cases.

The numbers in parentheses in Table 1 represent the number of cases (out of 20) Table 1

Mean Number of States Recalled and Median Number of Seconds Spent in Recall

\begin{tabular}{lll}
\multicolumn{1}{c}{ Group } & $\begin{array}{c}\text { Mean } \\
\text { Number } \\
\text { of States }\end{array}$ & $\begin{array}{c}\text { Median } \\
\text { Seconds }\end{array}$ \\
\hline Instructed Group & & \\
M States & $7.00(7)$ & $186(8)$ \\
N States & $7.60(13)$ & $132(6)$ \\
Combined & 7.30 & 146 \\
Uninstructed Group & \\
M States & $5.40(1)$ & $68(0)$ \\
N States & $6.15(3)$ & $70(0)$ \\
Combined & 5.78 & 70 \\
\hline
\end{tabular}

Note-Numbers in parentheses refer to number of Ss achieving maximum score. in which a maximum score of either eight states recalled or 240 sec spent on the task was attained. Thus, while there was a total of 14 instances of an $S$ being stopped after $240 \mathrm{sec}$ in Group I, the longest any $S$ in Group NI worked was $162 \mathrm{sec}$.

$$
\text { DISCUSSION }
$$

The results are straightforward. One group of Ss, informed that there were eight states to be listed, worked twice as long at the same task as a group not informed of the set size. This persistence paid off in an average of 1.5 additional states.

Although these results may seem a demonstration of what is intuitively obvious, the opposite outcome seems intuitively appealing as well. Why did not the uninformed Ss continue to work longer? After all, only Group I had been supplied with a quitting rule by E. Clearly, the $S_{5}$ of Group NI terminated retrieval for other reasons. It is highly unlikely that the state names were less available to them. The fact that Group NI did not work as long as Group I did may indicate an interaction between task dimensions and quitting rules. For instance, for very small sets, e.g., states beginning with the letter "U," Ss uninformed about set size might be expected to work longer than an informed $S$. That is, an $S$ told that there is only one such state can write down "Utah" and tum in his paper. For much larger sets of the kind typically used in free-recall experiments, specification of set size probably has little effect.

The experimental analysis of what variables do influence search termination cannot yet be said to have begun in earnest. In the present case, we can do no more than speculate as to the possible quitting rules adopted by all Ss, other than those in the instructed group who managed to retrieve all eight target states. However, the measurement of the time actually spent in the recall process by Ss may be a fruitful procedure in this regard. Typically, a generous but fixed amount of time for recall is allowed by $E$. How much of this time is, in fact, used by $S$ is not known unless some operation defining the end of retrieval is adopted.

\section{REFERENCES}

ATKINSON, R. C., \& SHIFFRIN, R. M. Human memory: A proposed system and its control processes. In K. W. Spence and J. T, Spence (Eds.), The psychology of leaming and motivation Vol. 2. New York: Academic Press, 1968. Pp. 119-122.

TULVING, E., \& PEARLSTONE, Z. Availability versus accessibility of information in memory for words. Journal of Verbal Learning \& Verbal Behavior, 1966, 5, 381-391. 